\title{
Affective disorders: A question of continuing treatment during pregnancy (Review)
}

\author{
SIMONA CORINA TRIFU ${ }^{1 *}$, ALEXANDRA POPESCU $^{2 *}$ and MARIA ALINA MARIAN ${ }^{2 *}$ \\ ${ }^{1}$ Department of Neurosciences, 'Carol Davila' University of Medicine and Pharmacy, 020021 Bucharest; \\ ${ }^{2}$ Department of Psychiatry, 'Alex. Obregia' Clinical Hospital of Psychiatry, 041914 Bucharest, Romania
}

Received June 2, 2020; Accepted July 2, 2020

DOI: $10.3892 / \mathrm{etm} .2020 .8989$

\begin{abstract}
Fetal development, especially in the first trimester, has proven to be heavily influenced by external factors, such as chemical intake of medication. Chronic psychiatric treatment might interfere with the anatomical and physiological wellbeing of the fetus, because psychotropic medication proceeds past the placenta, into the amniotic fluid, and can enter breast milk. Hence some of the medications prescribed for mood disorders should be reconsidered during pregnancy, without sub-optimally treating when it is needed. A literature review is presented which systematically collects modern data and synthesizes previous interdisciplinary research findings on the safety of psychiatric treatment for affective disorders during pregnancy (term-based) and lactation. Antidepressants and mood stabilizers, fundamental strategies in treating affective disorders, have been classified by the FDA as $\mathrm{C}$ respectively $\mathrm{D}$ drugs pertaining to their risk, with some exception. Most guidelines recommend pharmacologically treating moderate-severe depression, preferably with SSRIs. Evidence advocates that drugs should be used during pregnancy only if clearly needed and the benefit outweighs the risk to the fetus. However, guidelines the American College of Obstetricians and Gynecologists state that antidepressants are a preferred first course of treatment and does not take into account the severity of the depression. Among mood-stabilizers, lithium is considered to be the safest option for pregnant women. Anticonvulsants have a higher risk of teratogenicity compared with lithium, with lamotrigine being the safest one. All mood stabilizers should be recommended in the lowest effective doses. There is controversy regarding the safety of second-generation antipsychotics during pregnancy
\end{abstract}

Correspondence to: Dr Simona Corina Trifu, Department of Neurosciences, 'Carol Davila' University of Medicine and Pharmacy, 37 Dionisie Lupu Street, 020021 Bucharest, Romania

E-mail: simona.trifu@umfcd.ro

${ }^{*}$ Contributed equally

Key words: perinatal psychiatry, teratogenesis, neonatal toxicity, neurodevelopment, antidepressants, mood stabilizers, electroconvulsive therapy and further research is required. Several case reports and meta-reviews have been published in order to emphasize the safety of electroconvulsive therapy (ECT) during pregnancy, but practitioners still stigmatize this procedure. Evaluating the overall risk-benefit ratio should be assessed by the medical care provider, taking into consideration current findings.

\section{Contents \\ 1. Introduction \\ 2. Risk of prenatal depression \\ 3. Antidepressants \\ 4. Mood stabilizers \\ 5. Second-generation antipsychotics (SGAs) \\ 6. Electroconvulsive therapy (ECT) \\ 7. Conclusions}

\section{Introduction}

Throughout the years, psychiatric patient pregnancies have suffered multiple controversies. At some point in history continuing the pregnancy to term was highly discouraged, borderline illegal in some places of the world depending on the diagnosis. Having said this, the studies dedicated to psychopharmacology behind mental diseases in pregnancy are relatively new. Both doctors and patients have concerns and unanswered questions regarding the safety of medications during pregnancy and lactation. In this medical review we highlight chronic care in depression and bipolar disorder. The hormonal fluctuation that occurs during pregnancy is often a triggering factor for first episodes. Simultaneously chronic disorders are at risk of exacerbation when pregnant. Left untreated mental illnesses have been linked to cause their own set of problems, either by harmful behavior (neglecting perinatal care, drugs and alcohol, direct injury), or by stress. Prenatal stress has been tied by a series of studies to have a negative influence on the pregnancy outcome through hypothalamo-pituitary-adrenal pathway, inducing inflammation.

Our research team's experience is rich in the treatment of major depressive episodes developed in any trimester of pregnancy, the predominant options being for SSRI (mainly sertraline and fluvoxamine) and as an enhancer when the 
episode in question overlapped psychotic phenomena - olanzapine, risperidone or aripiprazole. Also, in the confusing episodes or with slow clinical evolution, we opted for clozapine or performed between 4-6 electroconvulsive treatment sessions. The literature, both old and modern, postulates relative and absolute contraindications in the use of mood stabilizers in pregnancy, the danger of lithium being well known, as well as the teratogenic effects of carbamazepine and valproate. Consequently, antidepressants remain first-line and mood stabilizers will be tried with modern antipsychotics, validated by the FDA as affective modulators.

The discussion touches on the teratogenic risk as well as neonatal toxicity associated with antidepressants (SSRIs, SNRIs, tricyclic and atypical), mood stabilizers also the benefits versus risks of ECTs as an alternative treatment. Regarding the classification of medicine based on their risks we used the universal scaling system as presented in Table I (1).

\section{Risk of prenatal depression}

Osborne et al (2) conducted an observational study on cortisol-stress reactivity due to prenatal depression and the effects on development up to a year, by comparing a case group of major depression disorder diagnosed women (and their offspring) to a control group of healthy pregnant women (and their offspring), concluding the following: i) abnormal stress-related biology (inflammation and cortisol) in pregnancy; ii) shorter length of gestation; iii) neonates with sub-optimal neurobehavioral function; iv) one-year-old infants with increased cortisol reactivity to stress.

This analysis did not include cases that overlapped other psychiatric diagnosis other than co-morbid anxiety disorder, or those with antidepressant medication at baseline. Premature labor is not the only negative finding current research ties to prenatal depression (3). Some evidence indicates low birth weight and intrauterine growth restriction. Results are ultimately inconclusive due to the interference of bio-psycho-social risk factors (4).

Others studies suggest that even mild depressive symptoms may be associated with a rise in inflammatory markers during early to mid-gestation (5). Timing is another key factor; maternal cortisol levels at different stages of gestation have various effects on the development of the babies. Exposure during early gestation was associated with a slower rate of cognitive development over the first 12 months, whilst exposure during the later stages had the opposite result (6). Whereas Braithwaite et al (7), implied that depression in the second and third trimester was not associated with cortisol reactivity to acute stress, or infant hyper-cortisol reactivity.

Considering the above, stress induced by depression can alter neurodevelopment, especially in the first trimester of gestation, deducing that treating depression might reduce stress and lower the risks, however, further investigation is needed.

\section{Antidepressants}

Narrowing negative outcomes (cardiovascular malformation, pulmonary hypertension, sub-optimal neurobehavioral function, premature birth, low weight on delivery) to antidepressants alone is difficult; considering that genetics and other hereditary issues such as the underlying maternal mental illness as well as lifestyle can contribute to deformities. Over time the puerperal use of antidepressants has increased, although opinions are yet divided $(8,9)$. The challenges faced by the health care providers are to identify an optimal treatment plan considering associated endocrine particularities or work burnout syndrome (10), when research on the topic is still scarce.

i) Selective serotonin reuptake inhibitors (SSRIs). SSRIs are first-line pharmaceuticals in treating depression as well as the favored antidepressants during pregnancy, with an international prevalence estimate of $3.0 \%$ (95\% CI, 2.3; 3.7) because of their safety profile. Moreover, among SSRIs the preferred substance was sertraline followed by citalopram (8).

On the other hand we came across contradictory evidence advocating that SSRIs may alter villous trophoblast syncytialization in a structure- and concentration-dependent manner, which may result in an imbalance of oxygen and nutrient exchange between the mother and fetus, and the production of pregnancy hormones crucial for fetal development and physiological adaptation of the mother (11). Secondly, the gestational use of SSRIs during organogenesis in the first trimester has been linked by a series of studies to be responsible of malformation, more commonly with septal defects (right ventricular outflow tract defects, atrial septal defects) (12-15) neural tube defects $(14,16)$, craniosynostosis, abdominal wall defects (omphalocele) $(14,17)$ and hypospadias $(14,18)$. Records also display a risk of spontaneous abortion due to severe life-incompatible malformation following the use of SSRIs during pregnancy (19).

Furthermore, women who received SSRIs during pregnancy had a significantly higher risk of developing preterm birth (PTB) compared with control groups. However, we should not forget that PTB is also frequently encountered in MDD cases thus giving grounds for more research $(20,21)$.

One important specification is that administering SSRIs during the last trimester of pregnancy may result in temporary (48-96 h) signs of withdrawal on delivery after in utero exposure, the primary manifestations being irritability, tremor, sleep disturbance, reduced appetite, hypotonicity or myoclonus, respiratory distress (22).

Childhood afflictions, such as autism spectrum disorder (ASD) and attention deficit hyperactivity disorder (ADHD) have been tried to be explained by in utero exposure to SSRIs in multiple studies, have conflicting results $(23,24)$. The contradicting data has generated more questions than answers.

Sertraline (C-category). Accumulating data indicate sertraline as a first line of treatment for MDD in pregnant patients, especially for new patients. Sertraline is also the preferred postnatal antidepressant used during lactation due low levels of exposure in breastfeeding infants and few adverse events described in case reports (25). Available studies recommend dose monitoring of sertraline throughout the pregnancy, aiming towards lowest therapeutically effective serum concentrations of sertraline in maternal blood. According to the said study a relatively low penetration into fetal circulation may contribute to a sufficient safety profile of sertraline during pregnancy (26). 
Table I. Safety of psychiatric medications during pregnancy and lactation (1).

\begin{tabular}{|c|c|c|}
\hline Drug & FDA pregnancy category ${ }^{\mathrm{a}}$ & Lactation category $^{\mathrm{b}}$ \\
\hline \multicolumn{3}{|c|}{ Antiepileptics and mood stabilizers } \\
\hline Carbamazepine & $\mathrm{D}$ & $\mathrm{L} 2$ \\
\hline Lamotrigine & $\mathrm{C}$ & L3 \\
\hline Lithium & $\mathrm{D}$ & L4 \\
\hline Valproic acid & $\mathrm{D}$ & $\mathrm{L} 2$ \\
\hline \multicolumn{3}{|l|}{ Antidepressants } \\
\hline \multicolumn{3}{|c|}{ Tricyclic and heterocyclic } \\
\hline Amitriptyline & $\mathrm{C}$ & $\mathrm{L} 2$ \\
\hline Amoxapin & $\mathrm{C}$ & L2 \\
\hline Clomipramine & $\mathrm{C}$ & $\mathrm{L} 2$ \\
\hline Desipramine & $\mathrm{C}$ & $\mathrm{L} 2$ \\
\hline Doxepin & $\mathrm{C}$ & L5 \\
\hline Imipramine & $\mathrm{C}$ & $\mathrm{L} 2$ \\
\hline Maprotiline & B & L3 \\
\hline Nortriptyline & $\mathrm{C}$ & $\mathrm{L} 2$ \\
\hline Protriptyline & $\mathrm{C}$ & NA \\
\hline \multicolumn{3}{|c|}{ Selective serotonin reuptake inhibitors } \\
\hline Citalopram & $\mathrm{C}$ & L3 \\
\hline Escitalopram & $\mathrm{C}$ & L3 in older infants \\
\hline Fluoxetine & $\mathrm{C}$ & L2 in older infants; L3 in neonates \\
\hline Fluvoxamine & $\mathrm{C}$ & $\mathrm{L} 2$ \\
\hline Paroxetine & $\mathrm{D}$ & L2 \\
\hline Sertraline & $\mathrm{C}$ & $\mathrm{L} 2$ \\
\hline \multicolumn{3}{|c|}{ Other antidepressants } \\
\hline Bupropion & $\mathrm{B}$ & L3 \\
\hline Duloxetine & $\mathrm{C}$ & NA \\
\hline Mirtazapine & $\mathrm{C}$ & L3 \\
\hline Nefazodone & $\mathrm{C}$ & L4 \\
\hline Trazodone & $\mathrm{C}$ & L2 \\
\hline Venlafaxine & $\mathrm{C}$ & L3 \\
\hline
\end{tabular}

${ }^{a}$ FDA classifies drug safety using the following categories: A, controlled studies show no risk; B, no evidence of risk in humans; $\mathrm{C}$, risk cannot

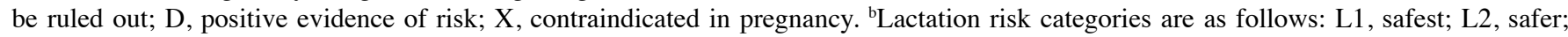
L3, moderately safe; L4, possibly hazardous; L5, contraindicated. The Table has been adjusted to present data relevant to this article by selecting information regarding antidepressants and mood stabilizers, common medication used in treating depression.

Citalopram (C-category). To quote a study: Citalopram used during embryogenesis is not associated with a major malformation risk, but administered later in pregnancy it may provoke poor neonatal adaptation syndrome (27).

Escitalopram (C-category). Escitalopram has a good safety profile during pregnancy and breastfeeding, however, findings have suggested a higher risk of spontaneous abortion in some studies, which should not be overlooked (28).

Fluoxetine (C-category). First of all, studies on fluoxetine are more easy-accessed compared with some other SSRIs. It appears that the use of fluoxetine in mothers, during pregnancy and breast-feeding changed the response of the serotonergic and adrenergic receptor systems of newborns (29). A study identified long-term change in cortical cytoarchitecture with a decrease in the complexity of the dendritic tree of cortical layer 2/3 pyramidal neurons as a consequence of in utero fluoxetine exposure which results in an increased anxiety-like behavior (30).

Fluvoxamine (C-category). Fluvoxamine is mostly known for treating obsessive-compulsive disorder and is not as widely used in comparisons to other SSRI medication for depression. No well-controlled studies have been done in humans. Glazova et al (31), in 2014, conducted a study stating that fluvoxamine administration at early developmental stages leads to a delay in physical and motor development.

Paroxetine (D-category). Paroxetine is generally discouraged during pregnancy, distinctly during organogenesis. Research demonstrates a high risk for cardiovascular malformation 
(mainly ventricular or atrial septal defects) when treating prenatal depression with paroxetine (32).

ii) Serotonin and norepinephrine reuptake inhibitors (SNRIs). The is limited publishing found on the topic of SNRIs, recommendations regarding the use of SNRIs are correlated to SSRIs in most studies regarding antenatal exposure.

Venlafaxine (C-category). Most research suggests a low risk in using venlafaxine during pregnancy, yet opposing evidence is presented as follows: The use of venlafaxine in early pregnancy may be associated with an increase in spontaneous abortions and urogenital disorders (33). A new study also suggests a link between the use of venlafaxine during pregnancy and an increased risk of gestational diabetes (34). Holland and Brown (35) in their medical review describe the possibility of venlafaxine fetal withdrawal syndrome after antenatal exposure. The withdrawal syndrome includes the preceding signs and symptoms: poor feeding, jitteriness, respiratory distress and myoclonic seizure-like activity (with no electroencephalographic abnormalities) lasting up to 21 days.

Duloxetine (C-category). Duloxetine is unlikely to be a major teratogen although it may slightly increase the risk of cardiovascular malformations. It has also been associated by some researchers with postpartum hemorrhage (36).

iii) Tricyclic antidepressants (TCAs). It has been suggests that a preference of TCAs over SSRIs in early pregnancy is not justified. The undesired outcomes associated with SSRIs have been described with use of TCAs during gestation as well, such as cardiovascular malformation and prenatal antidepressant exposure syndrome. However, we expect to see less neonatal persistent pulmonary hypertension when prescribing TCAs to pregnant women. According to this medical report Clomipramine (C-category) is associated with more severe and prolonged neonatal symptoms, whereas Nortriptyline (C-category) seems to be safest medication for use during breastfeeding (37).

Previous guidelines released by NICE on the use of antidepressants during pregnancy and lactation presents the following results: a) The risks of taking TCAs during pregnancy and when breastfeeding is better established than those of newer drugs, although the issues of tolerability and risk in overdose remain. b) TCAs, such as Amitriptyline, Imipramine and Nortriptyline - C-category, have lower known risks during pregnancy than other antidepressants (38).

Doxepin (C-category) is contraindicated during lactation, it excretes into the breast milk, risking drowsiness and apnea as studies suggest (39).

\section{iv) Other antidepressants}

Bupropion (B-category). Although not a favored antidepressant among non-pregnant women, its safety profile makes it a great candidate for treating depression during gestation. Analyzing data of pregnant women exposed to bupropion in the first trimester finds no increased risk of congenital malformations overall (40). Moreover, miscarriage rates are similar to other studies examining the safety of antidepressants during pregnancy (41).
Trazodone (C-category). Results suggest no increase of rates of major malformations, similar to nefazodone (C-category) (42).

Mirtazapine (C-category). It has a low teratogen risk. Yet one study identifies higher rates of spontaneous abortions in pregnant women when using mirtazapine (43).

\section{Mood stabilizers}

For the treatment of bipolar affective disorder (BPAD), refractory major depression and psychotic disorders, mood-stabilizing medication is used, such as antiepileptic drugs (valproate, lamotrigine, carbamazepine), lithium (the most prescribed in BPAD in comparison with other mood-stabilizers) and second-generation antipsychotics, which are increasingly prescribed in recent years $(44,45)$.

It has been found that women diagnosed with BPAD who interrupt their medication during pregnancy have a 3 times higher risk to relapse (46). Also, by interrupting the medication for BPAD during pregnancy, there is evidence that the neurodevelopment of the children may be affected (47).

i) Lithium (D-category). Lithium is almost exclusively renally eliminated and the factors which influence its pharmacodynamic are: age, renal function (lithium plasma level decreases because of the increase in renal blood flow and GFR, especially in the third trimester of pregnancy), weight, pregnancy, lactation and other drugs administered simultaneously (48).

Some studies concluded that lithium does not have negative impact on neurodevelopment, but further research is needed for studying longer term developmental outcomes in children exposed to lithium in utero $(49,50)$. Lithium is considered the safest mood-stabilizer that can be used for the treatment of pregnant women, due to the small absolute risk of cardiovascular anomalies such as Ebstein's anomaly, even though this risk is 10-20 times higher than in the general population (51).

Other studies suggest a link between lithium treatment and the risks of miscarriage, anencephaly, premature closure of arterial duct, oromandibular-limb hypogenesis, large for gestational age infants, neonatal hypothyroidism, polyhydramnios, nephrogenic diabetes insipidus, lower IQ (with normal overall intelligence), but there are no results on the negative impact of lithium treatment on general development, growth and behavior $(52,53)$.

Pregnant women in treatment with lithium should not be recommended doses greater than $400 \mathrm{mg}$ thrice a day (54). During pregnancy, the recommended lithium dose is the lowest effective one. The lithium level should be checked every trimester (for patients on stable doses of lithium), or monthly (for women who reinitiate the drug, or for those who suffer from hyperemesis gravidarum or dehydration, comorbidities that affect the absorption or the clearance of the drug). Twenty-four hours after delivery, therapeutic lithium levels should be checked, given the fact that after delivery the drug serum concentration increases due to the rapid decrease of the vascular volume (48).

ii) Anticonvulsants. The teratogenic risk of anticonvulsants is higher compared with lithium especially when multiple anticonvulsants are used simultaneously. Women of childbearing 
age who are treated with anticonvulsants should also take 4-5 mg folic acid daily in order to reduce the risk of neural tube defects (48).

Valproic acid (D-category). Valproat is useful in the management and prevention of both maniac and depressive episodes. Alone, or combined with another antiepileptic drug, it is associated with the greatest risk of teratogenicity of all the mood stabilizers (55). Therefore, VPA should not be prescribed for most women of childbearing age with BPAD (56).

The unbound drug is responsible for its pharmacologic activity. It has been observed that at the end of the third trimester of pregnancy there is an increase in the clearance of Valproic acid, with a consequent drop in its serum level. Researchers noted that even if the total level of VPA declines, free VPA levels remain the same, so measuring the levels of total and free plasma VPA during pregnancy is required. It has been discovered that VPA can cause drug toxicity because of its enzyme inhibition activity and consequent increase in drugs concentrations (48).

A dose-response relationship was found for doses higher than $800-1000 \mathrm{mg}$, there is a risk of poor neurodevelopment in children exposed in utero to valproat in comparison to those from the general population, with a 9.7 points drop in the IQ score, an eight times higher probability of an IQ $<85$ and lower verbal abilities (57).

Other studies also discovered motor skills and socialization deficiencies, as well as a higher risk of autistic traits than in the general population (58) lower originality (59) and attention deficit hyperkinetic disorder (60).

Studies have suggested that valproic acid and its derivatives have a negative effect on the closure of neural crest, thus, there is a 2-10-fold higher risk of neural tube defects (involving more often the lumbosacral) if used during pregnancy. It has also been associated with genital anomalies, cardiovascular malformations, hydrocephalus, slow intrauterine growth, pulmonary atresia and limb defects. In addition, a link has been found between the use of valproic acid during the first trimester and a higher risk of atrial septal defect, cleft palate, hypospadias, craniosynostosis and polydactyly (53).

Regarding the use of valproat in the third trimester, close to delivery, research suggests an association with feeding difficulties, abnormal tone, irritability (61), heart rate deceleration, hypoglycemia and liver toxicicty (60).

Lamotrigine (C-category). Lamotrigine is considered the safest mood-stabilizer for pregnant patients (62-64), because of its low risk of inducing fetal malformations and impaired cognitive development, but more studies are needed in order to identify more precisely possible major anomalies related to in utero exposure to lamotrigine.

It was not found to have an effect on the IQ score of children exposed in utero (57,58). Although the North American Antiepileptic Drug Pregnancy Registry suggested an increased risk for oral clefts, a prospective comparative observational study found no differences between the control group and the lamotrigine-exposed one (63). This result is sustained also by a large sample size study on orofacial cleft and congenital anomalies after lamotrigine use during pregnancy $(65,66)$. A recent systematic review analyzed 21 studies on rates of congenital malformations after in utero exposure and the results were similar to those found in the general population (67). It has been suggested that doses higher than $300 \mathrm{mg} /$ day increase the risks (68).

The metabolization of lamotrigine occurs in the liver and the enzymes responsible for this process are induced by pregnancy (69). So, lamotrigine clearance increases progressively and in order to maintain a therapeutic drug concentration, a dose increase is required (70). This change of the dose should be guided by clinical response. After delivery, drug plasma levels increase during the first 2-3 weeks after delivery, return to baseline and a dose adjustment is needed (48). If after delivery the dose is not modified, the patient may experience symptoms of toxicity (ataxia, nausea, vomiting, dizziness) (71).

Carbamazepine (D-category). Carbamazepine is not linked to a lower IQ, but it can cause lower verbal abilities. Carbamazepine use during pregnancy may also cause growth retardation, microcephaly, spina bifida, craniofacial abnormalities, transient hepatic toxicity (72), the risk being dose-dependent (maximum $400 \mathrm{mg} /$ day) (73).

The metabolization is hepatic, clearance increases in pregnancy and the metabolism of other medications administered simultaneously can increase, resulting in lower drug concentrations and effects (74).

Oxcarbazepine (D-category). The malformation risk in children exposed in utero (ventricular septal defects, facal malformations, congenital hydronephrosis, major urinary tract defect, spina bifida cystica, clubfoot) is similar to that seen in the general population (75). At the same time a recent case report described a 12-hour-old newborn with neonatal abstinence syndrome which resolved by day 9 of life (76).

Topiramate (D-category). Topiramate given during pregnancy has been documented to cause major malformations in $4.2-9 \%$ of the cases. The most reported malformations are cleft lip (especially when Topiramate is used during the first trimester) (77), low weight for gestational age, microcephaly, palate or limb and even respiratory or cardiovascular anomalies $(78,79)$.

Gabapentin (C-category). There are limited reports regarding its safety when used during pregnancy but one observational study concluded that it has not been associated with any major malformations. Although findings show high rates of preterm births, low weight at birth and an increased need of therapeutic abortions (80). Further investigation is required in order to have some statistically significant results.

\section{Second-generation antipsychotics (SGAs)}

SGAs are commonly prescribed as an adjuvant medication for affective disorders to reproductive-age women. Regarding the safety of second-generation antipsychotics during pregnancy, there is controversy and a large gap in research data.

A systematic review found a transient delay in the neurodevelopment of children exposed in utero to SGA (olanzapine, aripiprazole, quetiapine, ziprasidone, risperidone), which resolved by the age of 12 months (58). Another review concluded that while aripiprazole, quetiapine and olanzapine 
do not increase the risk of major congenital malformations, risperidone and paliperidone might associate a minor risk (81).

i) Aripiprazole (C-category). Available data do not show a high risk of malformation (82), but some studies found an elevated risk of lower birth weight, pregnancy hypertension and shorter gestation. Furthermore, aripiprazole is unlikely to cause gestational diabetes (83).

The first case report on long acting injectable aripiprazole, which was published in 2019, described no congenital malformations (84).

Quetiapine (C-category). Quetiapine is metabolized by cytochrome $\mathrm{P} 450$, which is upregulated in pregnancy.

In consequence, the plasma concentration of the drug decreases, requiring a dose increase during pregnancy. Literature suggests monthly clinical evaluation in order to detect the symptoms of depressive or maniacal episodes and to adjust the dose of quetiapine accordingly (85). The drug has not been related to major malformations $(86,87)$.

Olanzapine (C-category). From the scarce data available, the fetal outcomes are not different from the ones reported in the general population with the use of olanzapine in pregnancy. It is recommended to be used with caution during pregnancy, only if the benefits overweigh the potential risk to the fetus (88). There is evidence that women without diabetes, treated with olanzapine before pregnancy, have a higher risk of gestational diabetes in comparison to those who interrupt their treatment (89).

Risperidone (C-category). Risperidone use during pregnancy might increase the risk of major congenital abnormalities (84). On the other hand, there is no evidence of increased risk of gestational diabetes (89).

\section{Electroconvulsive therapy (ECT)}

ECT is an effective treatment for catatonia, severe depression, psychotic agitation, high suicidal risk, severe physical decline, medication-resistant illness, or endangerment regarding the adverse effects of drugs.

Pregnant women are at a higher risk when treated with drugs (premature delivery, low birth weight) and are prone to breakdown during pregnancy, even if they were not diagnosed with a psychiatric disorder before. Of all mood disorders, BDAD has been found to relapse the most frequently among pregnant women who interrupt their psychotropic treatment $(>70 \%)$. ECT is still stigmatized as a treatment for pregnant women with psychiatric disorders, one of the most significant reasons being the absence of codified practice guidelines for this population (90).

In order to make the best decision regarding the use of ECT on pregnant patients, doctors must take into consideration the risks of alternative treatment options and the consequences of the untreated psychiatric illness. The risks of ECT in pregnancy are not higher than the risks identified in the general population. In pregnant patients, the risks that occurred most often were premature contractions and preterm labor, but the frequency of their occurrence was not high and a clear link between ECT and this adverse effect has not been established. Moreover, ECT has not been associated with neurocognitive disturbances in children, congenital morphologic, behavioral abnormalities or miscarriage (91).

The authors of a meta-review listed fetal bradycardia/arrhythmia, premature birth, development delay, abdominal pain, uterine contraction, vaginal bleeding, placental abruption as the most frequent events that occurred when treating pregnant patients with ECT, but after analyzing the available data, they ended up supporting the fact that the administration of ECT in pregnancy is relatively safe (92). The same conclusion was drawn after research activity on ECT used in the first trimester of pregnancy, when only 1 patient out of 32 experienced a threatened abortion (93).

Ward et al (91) took into consideration the accumulated experience of 3 different medical centers from the US to formulate a guideline for the use of ECTs in pregnancy, which has not yet gained universal approval. Regarding anesthesia, Succinylcholin is safe to use during gestation. In order to avoid aortocaval compression which can cause fetal hypoxia, the pregnant patient must be placed in a left lateral decubitus position. Also, it is recommended to monitor fetal heart beats before and after each ECT.

Although several case reports and meta-reviews have been published that emphasize the safety of ECT upon pregnant women, the practitioners are still reluctant on this issue.

\section{Conclusions}

This medical review serves to aid clinicians with perinatal psychiatry, by sharing experience, to help answer the question whether to continue treatment during pregnancy, as proposed in the title. Ideally pharmaceutics should be allotted for moderate-severe cases while mild cases should initially seek alternative treatment methods (psychotherapy, physical activity, meditation, mindfulness) in order to reduce stress, which could have a negative effect on child development. The overall risk-benefit ratio should be assessed by the health care provider and treated accordingly.

\section{Acknowledgements}

Not applicable.

\section{Funding}

No funding was received.

\section{Availability of data and materials}

Not applicable.

\section{Authors' contributions}

SCT contributed in all the stages of the article, designed the study and revised the manuscript for important intellectual content. AP and MAM acquired the data by screening the papers identified on Pubmed and drafted the manuscript. AP also revised the manuscript. All authors read and approved the final manuscript. 


\section{Ethics approval and consent to participate}

Not applicable.

\section{Patient consent for publication}

Not applicable.

\section{Competing interests}

The authors declare that they have no competing interests.

\section{References}

1. American College of Obstetricians and Gynecologists: ACOG Practice Bulletin No. 87 November 2007: Use of psychiatric medications during pregnancy and lactation. Obstet Gynecol 110: 1179-1198, 2007.

2. Osborne S, Biaggi A, Chua TE, Du Preez A, Hazelgrove K, Nikkheslat N, Previti G, Zunszain PA, Conroy S and Pariante CM: Antenatal depression programs cortisol stress reactivity in offspring through increased maternal inflammation and cortisol in pregnancy: The Psychiatry Research and Motherhood - Depression (PRAM-D) Study. Psychoneuroendocrinology 98: 211-221, 2018.

3. Trifu S, Vladuti A and Popescu A: Neuroendocrine aspects of pregnancy and postpartum depression. Acta Endocrinol (Bucur) 15: 410-415, 2019.

4. Grote NK, Bridge JA, Gavin AR, Melville JL, Iyengar S and Katon WJ: A meta-analysis of depression during pregnancy and the risk of preterm birth, low birth weight, and intrauterine growth restriction. Arch Gen Psychiatry 67: 1012-1024, 2010.

5. Azar R and Mercer D: Mild depressive symptoms are associated with elevated C-reactive protein and proinflammatory cytokine levels during early to midgestation: A prospective pilot study. J Womens Health (Larchmt) 22: 385-389, 2013.

6. Davis EP and Sandman CA: The timing of prenatal exposure to maternal cortisol and psychosocial stress is associated with human infant cognitive development. Child Dev 81: 131-148, 2010

7. Braithwaite EC, Murphy SE and Ramchandani PG: Effects of prenatal depressive symptoms on maternal and infant cortisol reactivity. Arch Women Ment Health 19: 581-590, 2016.

8. Molenaar NM, Bais B, Lambregtse-van den Berg MP, Mulder CL, Howell EA, Fox NS, Rommel AS, Bergink V and Kamperman AM: The international prevalence of antidepressant use before, during, and after pregnancy: A systematic review and meta-analysis of timing, type of prescriptions and geographical variability. $\mathbf{J}$ Affect Disord 264: 82-89, 2020.

9. Simoncelli M, Martin BZ and Bérard A: Antidepressant use during pregnancy: A critical systematic review of the literature. Curr Drug Saf 5: 153-170, 2010.

10. Trifu S: Neuroendocrine insights into burnout syndrome. Acta Endocrinol (Bucur) 15: 404-405, 2019.

11. Clabault H, Flipo D, Guibourdenche J, Fournier T, Sanderson JT and Vaillancourt C: Effects of selective serotonin-reuptake inhibitors (SSRIs) on human villous trophoblasts syncytialization. Toxicol Appl Pharmacol 349: 8-20, 2018.

12. Jimenez-Solem E, Andersen JT, Petersen M, Broedbaek K Jensen JK, Afzal S, Gislason GH, Torp-Pedersen C and Poulsen HE: Exposure to selective serotonin reuptake inhibitors and the risk of congenital malformations: A nationwide cohort study. BMJ Open 2: e001148, 2012.

13. Grigoriadis S, VonderPorten EH, Mamisashvili L, Roerecke M Rehm J, Dennis CL, Koren G, Steiner M, Mousmanis P Cheung A, et al: Antidepressant exposure during pregnancy and congenital malformations: Is there an association? A systematic review and meta-analysis of the best evidence. J Clin Psychiatry 74: e293-e308, 2013.

14. Jordan S, Morris JK, Davies GI, Tucker D, Thayer DS, Luteijn JM Morgan M, Garne E, Hansen AV, Klungsøyr K, et al: Selective serotonin reuptake inhibitor (SSRI) antidepressants in pregnancy and congenital anomalies: Analysis of linked databases in Wales, Norway and Funen, Denmark. PLoS One 11: e0165122, 2016

15. Wurst KE, Poole C, Ephross SA and Olshan AF: First trimester paroxetine use and the prevalence of congenital, specifically cardiac, defects: A meta-analysis of epidemiological studies. Birth Defects Res A Clin Mol Teratol 88: 159-170, 2010.
16. Malm H, Artama M, Gissler M and Ritvanen A: Selective serotonin reuptake inhibitors and risk for major congenital anomalies. Obstet Gynecol 118: 111-120, 2011.

17. Källén BAJ and Olausson PO: Maternal use of selective serotonin re-uptake inhibitors in early pregnancy and infant congenital malformations. Birth Defects Res A Clin Mol Teratol 79: 301-308, 2007.

18. Pop A, Lupu DI, Cherfan J, Kiss B and Loghin F: Estrogenic/antiestrogenic activity of selected selective serotonin reuptake inhibitors. Clujul Med 88: 381-385, 2015.

19. Nikfar S, Rahimi R, Hendoiee $\mathrm{N}$ and Abdollahi M: Increasing the risk of spontaneous abortion and major malformations in newborns following use of serotonin reuptake inhibitors during pregnancy: A systematic review and updated meta-analysis. Daru 20: 75, 2012.

20. Trifu S, Mihailescu R, Stegarescu S and Ion I: Evolutional perspective over some key-aspects in psychiatry. In: Theoretical and Applied in Psychology (SICAP23): Psychology and Ongoing Development. Zamosteanu A (ed.) Medimond s.r.l., Bologna, pp179-182, 2015

21. Eke AC, Saccone G and Berghella V: Selective serotonin reuptake inhibitor (SSRI) use during pregnancy and risk of preterm birth: A systematic review and meta-analysis. BJOG 123: 1900-1907, 2016.

22. Levinson-Castiel R, Merlob P, Linder N, Sirota L and Klinger G: Neonatal abstinence syndrome after in utero exposure to selective serotonin reuptake inhibitors in term infants. Arch Pediatr Adolesc Med 160: 173-176, 2006.

23. Man KK, Tong HH, Wong LY, Chan EW, Simonoff E and Wong IC: Exposure to selective serotonin reuptake inhibitors during pregnancy and risk of autism spectrum disorder in children: A systematic review and meta-analysis of observational studies. Neurosci Biobehav Rev 49: 82-89, 2015.

24. Morales DR, Slattery J, Evans S and Kurz X: Antidepressant use during pregnancy and risk of autism spectrum disorder and attention deficit hyperactivity disorder: Systematic review of observational studies and methodological considerations. BMC Med 16: 6, 2018

25. Pinheiro E, Bogen DL, Hoxha D, Ciolino JD and Wisner KL: Sertraline and breastfeeding: Review and meta-analysis. Arch Women Ment Health 18: 139-146, 2015.

26. Paulzen M, Goecke TW, Stickeler E, Gründer G and Schoretsanitis G: Sertraline in pregnancy - Therapeutic drug monitoring in maternal blood, amniotic fluid and cord blood. J Affect Disord 212: 1-6, 2017.

27. Sivojelezova A, Shuhaiber S, Sarkissian L, Einarson A and Koren G: Citalopram use in pregnancy: Prospective comparative evaluation of pregnancy and fetal outcome. Am J Obstet Gynecol 193: 2004-2009, 2005

28. Grossmann CK, Weitzner B, Pistelli A, Many A, Lessing J and Koren G: Escitalopram use in pregnancy: An observational cohort study. Am J Obstet Gynecol 206: S58, 2012.

29. Pereira JD, Caricati-Neto A, Jurkiewicz A and Jurkiewicz NH: Decreased noradrenergic and serotonergic reactivity of vas deferens of newborn rats from mothers treated with the serotonin reuptake inhibitor fluoxetine during pregnancy and breast-feeding. Life Sci 81: 1501-1508, 2007.

30. Smit-Rigter LA, Noorlander CW, von Oerthel L, Chameau P, Smidt MP and van Hooft JA: Prenatal fluoxetine exposure induces life-long serotonin $5-\mathrm{HT}_{3}$ receptor-dependent cortical abnormalities and anxiety-like behaviour. Neuropharmacology 62 : 865-870, 2012.

31. Glazova NY, Merchieva SA, Volodina MA, Sebentsova EA, Manchenko DM, Kudrun VS and Levitskaya NG: Effects of neonatal fluvoxamine administration on the physical development and activity of the serotoninergic system in white rats. Acta Naturae 6: 98-105, 2014.

32. Bar-Oz B, Einarson T, Einarson A, Boskovic R, O'Brien L Malm H, Bérard A and Koren G: Paroxetine and congenital malformations: meta-analysis and consideration of potential confounding factors. Clin Ther 29: 918-926, 2007.

33. Paulus WE: Risk of congenital malformations after maternal treatment with venlafaxine in early pregnancy. Reprod Toxicol 37: $87,2013$.

34. Dandjinou M, Sheehy $\mathrm{O}$ and Bérard A: Antidepressant use during pregnancy and the risk of gestational diabetes mellitus: A nested case-control study. BMJ Open 9: e025908, 2019.

35. Holland $\mathrm{J}$ and Brown R: Neonatal venlafaxine discontinuation syndrome: A mini-review. Eur J Paediatr Neurol 21: 264-268, 2017. 
36. Huybrechts KF, Bateman BT, Pawar A, Bessette LG, Mogun H, Levin R, Li H, Motsko S, Scantamburlo Fernandes MF, Upadhyaya HP, et al: Maternal and fetal outcomes following exposure to duloxetine in pregnancy: Cohort study. BMJ 368: 237, 2020.

37. Gentile S: Tricyclic antidepressants in pregnancy and puerperium. Expert Opin Drug Saf 13: 207-225, 2014.

38. National Collaborating Centre for Mental Health (UK): Antenatal and Postnatal Mental Health: The NICE Guideline on Clinical Management and Service Guidance. British Psychological Society, Leicester, 2007. https://pubmed.ncbi.nlm. nih.gov/21678630/

39. Armstrong C: ACOG Guidelines on psychiatric medication use during pregnancy and lactation. Am Fam Physician 78: 772-778, 2008.

40. Chun-Fai-Chan B, Koren G, Fayez I, Kalra S, Voyer-Lavigne S, Boshier A, Shakir S and Einarson A: Pregnancy outcome of women exposed to bupropion during pregnancy: A prospective comparative study. Am J Obstet Gynecol 192: 932-936, 2005.

41. Cole JA, Modell JG, Haight BR, Cosmatos IS, Stoler JM and Walker AM: Bupropion in pregnancy and the prevalence of congenital malformations. Pharmacoepidemiol Drug Saf 16: 474-484, 2007

42. Einarson A, Bonari L, Voyer-Lavigne S, Addis A, Matsui D, Johnson Y and Koren G: A multicentre prospective controlled study to determine the safety of trazodone and nefazodone use during pregnancy. Can J Psychiatry 48: 106-110, 2003.

43. Djulus J, Koren G, Einarson TR, Wilton L, Shakir S Diav-Citrin O, Kennedy D, Voyer Lavigne S, De Santis M and Einarson A: Exposure to mirtazapine during pregnancy: A prospective, comparative study of birth outcomes. J Clin Psychiatry 67: 1280-1284, 2006.

44. Trifu S, Delcuescu C and Boer CM: Psychosomatics and psychical tension (clinical research). Procedia Soc Behav Sci 33: 128-132, 2012.

45. Khan SJ, Fersh ME, Ernst C, Klipstein K, Albertini ES and Lusskin SI: Bipolar disorder in pregnancy and postpartum: Principles of management. Curr Psychiatry Rep 18: 13, 2016.

46. Wesseloo R, Kamperman AM, Munk-Olsen T, Pop VJ, Kushner SA and Bergink V: Risk of postpartum relapse in bipolar disorder and postpartum psychosis: A systematic review and meta-analysis. Am J Psychiatry 173: 117-127, 2016.

47. Gentile S: Lithium in pregnancy: The need to treat, the duty to ensure safety. Expert Opin Drug Saf 11: 425-437, 2012.

48. Deligiannidis KM, Byatt N and Freeman MP: Pharmacotherapy for mood disorders in pregnancy: A review of pharmacokinetic changes and clinical recommendations for therapeutic drug monitoring. J Clin Psychopharmacol 34: 244-255, 2014.

49. Forsberg L, Berglund G, Naver L, Ljungdahl M, Adler M and Wide K: Bipolar disorder and pregnancy-neurodevelopmental outcome of children exposed to maternal illness with or without lithium during pregnancy. Arch Dis Child 97 (Suppl 2): A184-A185, 2012.

50. van der Lugt NM, van de Maat JS, van Kamp IL, Knoppert-van der Klein EA, Hovens JG and Walther FJ: Fetal, neonatal and developmental outcomes of lithium-exposed pregnancies. Early Hum Dev 88: 375-378, 2012.

51. Cohen LS, Friedman JM, Jefferson JW, Johnson EM and Weiner ML: A reevaluation of risk of in utero exposure to lithium. JAMA 271: 146-150, 1994.

52. Trifu S: Dissociative identity disorder. Psychotic functioning and impairment of growing-up processes. J Educ Sci Psychol 9: 102-108, 2019

53. Grover S and Avasthi A: Mood stabilizers in pregnancy and lactation. Indian J Psychiatry 57 (Suppl 2): S308-S323, 2015

54. Horton S, Tuerk A, Cook D, Cook J and Dhurjati P: Maximum recommended dosage of lithium for pregnant women based on a PBPK model for lithium absorption. Adv Bioinforma 2012: 352729,2012

55. Veroniki AA, Rios P, Cogo E, Straus SE, Finkelstein Y, Kealey R, Reynen E, Soobiah C, Thavorn K, Hutton B, et al: Comparative safety of antiepileptic drugs for neurological development in children exposed during pregnancy and breast feeding: A systematic review and network meta-analysis. BMJ Open 7 : $\mathrm{e} 017248,2017$

56. Womersley K: Prescription of sodium valproate as a mood stabiliser in pregnancy. Psychiatr Danub 29 (Suppl 3): 679-684, 2017.

57. Haskey C and Galbally M: Mood stabilizers in pregnancy and child developmental outcomes: A systematic review. Aust N Z J Psychiatry 51: 1087-1097, 2017.
58. Deshmukh U, Adams J, Macklin EA, Dhillon R, McCarthy KD, Dworetzky B, Klein A and Holmes LB: Behavioral outcomes in children exposed prenatally to lamotrigine, valproate, or carbamazepine. Neurotoxicol Teratol 54: 5-14, 2016.

59. McVearry KM, Gaillard WD, VanMeter J and Meador KJ: A prospective study of cognitive fluency and originality in children exposed in utero to carbamazepine, lamotrigine, or valproate monotherapy. Epilepsy Behav 16: 609-616, 2009.

60. Gentile S: Risks of neurobehavioral teratogenicity associated with prenatal exposure to valproate monotherapy: A systematic review with regulatory repercussions. CNS Spectr 19: 305-315, 2014.

61. Koch S, Lösche G, Jager-Romän E, Jakob S, Rating D, Deichl A and Helge $\mathrm{H}$ : Major and minor birth malformations and antiepileptic drugs. Neurology 42 (Suppl 5): 83-88, 1992.

62. Kong L, Zhou T, Wang B, Gao Z and Wang C: The risks associated with the use of lamotrigine during pregnancy. Int J Psychiatry Clin Pract 22: 2-5, 2018.

63. Diav-Citrin O, Shechtman S, Zvi N, Finkel-Pekarsky V and Ornoy A: Is it safe to use lamotrigine during pregnancy? A prospective comparative observational study. Birth Defects Res 109: 1196-1203, 2017

64. Yasam VR, Jakki SL, Senthil V, Eswaramoorthy M, Shanmuganathan S, Arjunan K and Nanjan MJ: A pharmacological overview of lamotrigine for the treatment of epilepsy. Expert Rev Clin Pharmacol 9: 1533-1546, 2016.

65. Cohen-Israel M, Berger I, Martonovich EY, Klinger G, Stahl B and Linder N: Short- and long-term complications of in utero exposure to lamotrigine. Br J Clin Pharmacol 84: 189-194, 2018.

66. Dolk H, Wang H, Loane M, Morris J, Garne E, Addor MC, Arriola L, Bakker M, Barisic I, Doray B, et al: Lamotrigine use in pregnancy and risk of orofacial cleft and other congenital anomalies. Neurology 86: 1716-1725, 2016.

67. Pariente G, Leibson T, Shulman T, Adams-Webber T, Barzilay E and Nulman I: Pregnancy outcomes following in utero exposure to lamotrigine: A systematic review and meta-analysis. CNS Drugs 31: 439-450, 2017.

68. Tomson T, Battino D, Bonizzoni E, Craig J, Lindhout D, Sabers A, Perucca E and Vajda F; EURAP study group: Dose-dependent risk of malformations with antiepileptic drugs: An analysis of data from the EURAP epilepsy and pregnancy registry. Lancet Neurol 10: 609-617, 2011.

69. Tomson T, Landmark CJ and Battino D: Antiepileptic drug treatment in pregnancy: Changes in drug disposition and their clinical implications. Epilepsia 54: 405-414, 2013.

70. Ding Y, Tan X, Zhang S and Guo Y: Pharmacokinetic changes and therapeutic drug monitoring of lamotrigine during pregnancy. Brain Behav 9: e01315, 2019.

71. Tran TA, Leppik IE, Blesi K, Sathanandan ST and Remmel R: Lamotrigine clearance during pregnancy. Neurology 59: 251-255, 2002.

72. Baker GA, Bromley RL, Briggs M, Cheyne CP, Cohen MJ, García-Fiñana M, Gummery A, Kneen R, Loring DW, Mawer G, et al; Liverpool and Manchester Neurodevelopment Group: IQ at 6 years after in utero exposure to antiepileptic drugs: A controlled cohort study. Neurology 84: 382-390, 2015.

73. Frey B, Schubiger G and Musy JP: Transient cholestatic hepatitis in a neonate associated with carbamazepine exposure during pregnancy and breast-feeding. Eur J Pediatr 150: 136-138, 1990.

74. Ladea M and Prelipceanu D: Markers of vulnerability in schizophrenia. J Med Life 2: 155-164, 2009.

75. De Santis M, De Luca C, Mappa I, Cesari E, Quattrocchi T, Spagnuolo T, Visconti D and Caruso A: Antiepileptic drugs during pregnancy: Pharmacokinetics and transplacental transfer. Curr Pharm Biotechnol 12: 781-788, 2011

76. Chen CY, Li X, Ma LY, Wu PH, Zhou Y, Feng Q and Cui YM: In utero oxcarbazepine exposure and neonatal abstinence syndrome: Case report and brief review of the literature. Pharmacotherapy 37: e71-e75, 2017.

77. Mines D, Tennis P, Curkendall SM, Li DK, Peterson C, Andrews EB, Calingaert B, Chen H, Deshpande G, Esposito DB, et al: Topiramate use in pregnancy and the birth prevalence of oral clefts. Pharmacoepidemiol Drug Saf 23: 1017-1025, 2014.

78. Castilla-Puentes R, Ford L, Manera L, Kwarta RF Jr, Ascher S and $\mathrm{Li}$ Q: Topiramate monotherapy use in women with and without epilepsy: Pregnancy and neonatal outcomes. Epilepsy Res 108: 717-724, 2014.

79. Veiby G, Daltveit AK, Engelsen BA and Gilhus NE: Fetal growth restriction and birth defects with newer and older antiepileptic drugs during pregnancy. J Neurol 261: 579-588, 2014. 
80. Fujii H, Goel A, Bernard N, Pistelli A, Yates LM, Stephens S, Han JY, Matsui D, Etwell F, Einarson TR, et al: Pregnancy outcomes following gabapentin use: Results of a prospective comparative cohort study. Neurology 80: 1565-1570, 2013.

81. Damkier P and Videbech P: The safety of second-generation antipsychotics during pregnancy: A clinically focused review. CNS Drugs 32: 351-366, 2018.

82. Bellantuono C, Di Massimo G, Mauro A, Martellini M and Nardi B: Aripiprazole in pregnancy: A review of literature. Riv Psichiatr 50: 8-11, 2015 (In Italian).

83. Galbally M, Frayne J, Watson SJ and Snellen M: Aripiprazole and pregnancy: A retrospective, multicentre study. J Affect Disord 238: 593-596, 2018.

84. Ballester-Gracia I, Pérez-Almarcha M, Galvez-Llompart A and Hernandez-Viadel M: Use of long acting injectable aripiprazole before and through pregnancy in bipolar disorder: A case report. BMC Pharmacol Toxicol 20: 52, 2019.

85. Pinheiro EA, Wisner KL and Clark CT: Quetiapine dose adjustments in pregnant and postpartum women with bipolar disorder. J Clin Psychopharmacol 38: 89-91, 2018.

86. Cohen LS, Góez-Mogollón L, Sosinsky AZ, Savella GM, Viguera AC, Chitayat D, Hernández-Díaz S and Freeman MP: Risk of major malformations in infants following first-trimester exposure to quetiapine. Am J Psychiatry 175: 1225-1231, 2018.

87. Spinelli MG: Accurate assessment of risk of major malformations in infants with first-trimester exposure to quetiapine. Am J Psychiatry 175: 1161-1162, 2018.
88. Brunner E, Falk DM, Jones M, Dey DK and Shatapathy CC: Olanzapine in pregnancy and breastfeeding: A review of data from global safety surveillance. BMC Pharmacol Toxicol 14: 38 , 2013.

89. Park Y, Hernandez-Diaz S, Bateman BT, Cohen JM, Desai RJ, Patorno E, Glynn RJ, Cohen LS, Mogun H and Huybrechts KF: Continuation of atypical antipsychotic medication during early pregnancy and the risk of gestational diabetes. Am J Psychiatry 175: 564-574, 2018.

90. Pierre D, Péricaud A, Guerby P, Castel A, Schmitt L and Yrondi A: Bitemporal electroconvulsive therapy during the second trimester of pregnancy in bipolar disorders: A case report. J ECT 36: e14-e15, 2020.

91. Ward HB, Fromson JA, Cooper JJ, De Oliveira G and Almeida M: Recommendations for the use of ECT in pregnancy: Literature review and proposed clinical protocol. Arch Women Ment Health 21: 715-722, 2018.

92. Coshal S, Jones K, Coverdale J and Livingston R: An overview of reviews on the safety of electroconvulsive therapy administered during pregnancy. J Psychiatr Pract 25: 2-6, 2019.

93. Calaway K, Coshal S, Jones K, Coverdale J and Livingston R: A systematic review of the safety of electroconvulsive therapy use during the first timester of pregnancy. J ECT 32: 230-235, 2016.

c) (i) $\ominus$ This work is licensed under a Creative Commons Attribution-NonCommercial-NoDerivatives 4.0 International (CC BY-NC-ND 4.0) License. 